Running head: The moderating role of length of stay in the relationship between cognitive dysregulation and peer attachment in adolescents living in residential care

The moderating role of length of stay in the relationship between cognitive dysregulation and peer attachment in adolescent boys and girls living in residential care

Alexandra M. Lino ${ }^{1}$, Luiza Nobre Lima ${ }^{2}$ \& Lisete S. Mónico ${ }^{3}$

${ }^{1}$ Faculty of Psychology and Education Sciences, Rua do Colégio Novo, 3000-115 Coimbra, Portugal. E-mail: alexandra.imlino@gmail.com

${ }^{2}$ Cognitive and Behavioral Center for Research and Intervention (R\&D Unit)

Faculty of Psychology and Education Sciences, Rua do Colégio Novo, 3000-115 Coimbra, Portugal

E-mail: luizabelima@fpce.uc.pt

${ }^{3}$ Institute of Cognitive Psychology, Vocational and Social Development

Faculty of Psychology and Education Sciences, Rua do Colégio Novo, 3000-115 Coimbra, Portugal.

E-mail: lisete.monico@fpce.uc.pt 
Running head: The moderating role of length of stay in the relationship between cognitive

\section{The moderating role of length of stay in the relationship between cognitive dysregulation and peer attachment in adolescent boys and girls living in residential care}

\section{Date of Postage: November $12^{\text {th }}, 2016$}

\section{Abstract}

In Portugal, youth at risk tend to be placed in residential care for long periods of time, during which peers assume a status close to that of family. However, these adolescents often present deficits in emotional regulation, which can compromise the quality of their relationships with peers. Therefore, this study aimed to analyze the relationship between emotional dysregulation experienced by institutionalized adolescents and their own perception of peer attachment, testing whether the length of stay moderates this relationship, for boys and girls independently. Data was collected from a sample of 100 Portuguese adolescents (71 boys; 29 girls), aged 12-18, living in residential care for 43 months average $(\mathrm{SD}=43.14)$. They responded to the Abbreviated Dysregulation Inventory, which measures cognitive, affective and behavioral dysregulation, and the peer version of the Inventory of Parent and Peer Attachment, which measures communication, trust and alienation.

Only cognitive dysregulation accounted for the variability of perceived attachment to peers, in the total scale and in communication and trust. When the level of cognitive dysregulation reported by the adolescents is high, there is a positive effect of length of stay in the previous relationships, but only for boys.

Results outline how length of placement contributes to youth at risk to reach certain outcomes. They also emphasize the need to develop specific interventions in residential care contexts to address specific characteristics such as gender differences, in order to continuously promote positive interactions with peers in these contexts.

Keywords: adolescents in residential care, emotional dysregulation, peer attachment, length of stay, boys, girls

Funding Sources: This research did not receive any specific grant from funding agencies in the public, commercial, or not-for-profit sectors. 
Running head: The moderating role of length of stay in the relationship between cognitive dysregulation and peer attachment in adolescents living in residential care

\section{Introduction}

Residential care is the most significant protection measure for children and youth at risk in the Portuguese child welfare system (Browne, Hamilton-Giachritsis, Johnson \& Ostergre, 2006; Instituto da Segurança Social, I.P., 2016). Often perceived as a "last resort" solution, this measure places children and adolescents in short- or long-term residential group homes that shall attend to their best interest by providing the necessary conditions to promote a well-adjusted development (Goldstein, Solnit, Goldstein, \& Freud, 1996).

Considering that the new relationships these children will come to establish at the group homes with both staff and peers will have an important impact in their motivation to engage in more adaptive developme ntal pathways (Anglin, 2002; Nobre-Lima, 2009), it is relevant to better understand the conditions that influence the development and maintenance of such relationships, particularly with peers. Given that the time spent in these settings is a concern for the professionals that have to delineate a life project for these children, length of stay in residential care will be considered in this study along with gender, since boys and girls tend to experience out of-home placement differently (Chow, Mettrick, Stephan, \& Von Waldner, 2014).

Upon their arrival to residential homes, many adolescents already bring with them a set of problems and pre-existing difficulties that can affect their behavior and their experiences (Shaw \& Frost, 2013). The vast majority of them had a childhood characterized by experiences of abuse and/or neglect, to which in many other cases is added several unsuccessful placement experiences (Shaw \& Frost, 2013). As a consequence of these traumatic events experienced throughout their development, adolescents in residential care are likely to present several deficits with regard to self-regulation skills (Cook et al., 2005) that compromise the quality of the relationships they establish with others.

In fact, recent studies on the outcomes of children and youth in residential care settings have shown a high prevalence of emotional and behavioral disorders, as well as increased odds for comorbidity between them (Greger, Myhre, Lydersen \& Jozefiak, 2015). Also, when compared with adolescents who were adopted or who are in grandparent fostering, adolescents living in residential care exhibit higher levels of externalizing behavior problems (Fernández-Molina, del Valle, Fuentes, Bernedo, \& Bravo, 2011). With respect to their quality of life in general, these adolescents have scored poorly in domains such as their physical and emotional well-being, their self-esteem, and in their friendship and school relationships (Greger, Myhre, Lydersen, \& Jozefiak, 2016). They also show evidence of insecurity in their affective relationships, a negative self-concept, a weak perception of control over life events (meaning that they rely mostly on their luck), and low self-efficacy beliefs (Lázaro \& 
Running head: The moderating role of length of stay in the relationship between cognitive dysregulation and peer attachment in adolescents living in residential care

López, 2010). Analyzing gender differences between youth in residential care, Chow et al. (2014) show that institutionalized girls exhibited greater problems in functioning across major areas of life, building resources to protect against stress, and displaying safe behaviors towards self and others than institutionalized boys. Results from a study by Farruggia and Germo (2015), although referring to youth in foster care, also imply that girls might have a greater vulnerability to individual risk than boys.

Many of the adolescents placed in group homes typically suffer from significant social skills deficits, overaggressive and antisocial behaviors, fears of groups, distortions in reality assessment, hyperactivity, impulsiveness and other ego weaknesses (Gwyn, Meyer, \& Schaefer, 1993). They also present a significantly higher risk for delinquency when compared with adolescents in foster home placements (Ryan, Marshall, Herz, \& Hernandez, 2008). That might help to explain why peer violence in residential care settings has attracted special attention in recent years, presenting itself as a recurrent phenomenon (Barter, 2003, 2008).

The way adolescents are sometimes mistreated by their peers in the residential care context (Barter, 2003; Monks et al., 2009), especially in those situations in which older teens are put in charge of younger ones, has already been reported (Barter, 2008; Nobre-Lima, 2009). Along with the emotional and behavioral vulnerabilities considered above, this would contribute to the understanding of why adolescents who have experienced maltreatment have difficulties establishing relationships with peers (e.g. Cicchetti \& Toth, 2005; Shields \& Cicchetti, 2001; Trickett, Negriff, Ji \& Peckins, 2011). However, many of these adolescents' aggressive or hostile behaviors might indicate maladaptive expressions of a desire of proximity and acceptance, given that this is the only model of "affection" they know (Crittenden, 1992).

It is well known that peer relationships play a major role in the social and emotional development of children and adolescents as they have the ability to influence an individual's trajectory through life (Gorrese \& Ruggieri, 2012). The reciprocity of these relationships is, however, influenced by perceived trust and honesty (Rotenberg \& Bolton, 2013), which in turn are determined by the adolescents' ability to consider the perspectives of others (Fett et al., 2014). Yet, as trust reflects expectations based on affection felt from others, the constant violations of those expectations to which maltreated children and adolescents were exposed tend to cause intense emotional reactions to those same behaviors (Rotenberg, 2010). On this matter, studies concerning gender differences have shown that even though, normatively, girls tend to adopt more pro-social behaviors (Rose \& Rudolph, 2006), in comparison to boys they tend to trust others less, only expressing their emotions in return for the affection they receive (Derks, Lee, \& Krabbendam, 2014). 
Running head: The moderating role of length of stay in the relationship between cognitive dysregulation and peer attachment in adolescents living in residential care

In the residential care context, peer relationships become an important source of support for the adolescents (Emond, 2003; Morgan, 2009; Nobre-Lima, 2009), ensuring the presence of an individual in whom they can confide their most intimate thoughts (Nobre-Lima, 2009). By seeking the peer group in moments of greater anguish, the adolescents end up developing emotional bonds with some of its members that can, in certain ways, protect their development. As pointed out by Mota and Matos (2010, 2015), the adolescents' proximity to the peer group allows them to express their ideas and feelings, and to become empathetic and positively involved in the relationship with others, thus promoting the development of social skills. For the adolescent that has been removed from his family, the peer group acts as a substitute for the closest relatives as well as an adult influence with respect to emotional support, sense of status, and personal value (Shaw, 2014). This may be due to the fact that they are "often the only "chosen" and free relationships that the children experienced" (Emond, 2014, p. 200).

There has been much discussion on what impact the experience of institutionalization might have on children and adolescent development. MacLean (2003) has shown that children who are institutionalized early tend to present deficits in their growth and their cognitive development, more problems with behavior and attention span, and difficulties in their relationships with peers when compared with non-institutionalized children. These same studies found evidence that length of stay in the group home has continued costs to the child's development, correlating positively with the deficits found. In Portugal, recent studies with children living in residential care also showed a significant delay in the children's physical growth, deficits in their cognitive development, disturbed socio-emotional behaviors, and an even more difficult temperament (Pereira et al., 2010; Soares, Silva, Marques, Baptista, \& Oliveira, 2010). Additionally, these studies showed that children admitted to residential care before the age of 6 months are more likely to have cognitive, language and motor problems.

As for adolescents, Thompson et al. (1996) showed that residential care can lead to improvements in their academic performance and behavior, positively influenced by length of stay. According to Ringle, Ingram and Thompson (2010), being institutionalized for a long time allows young people to complete their high school education, which in turn, is an indicator of greater productivity in life. Similarly, the results of a study conducted by Lee and Thompson (2009), which intended to examine the externalizing behavior trajectories of institutionalized adolescents, also pointed to an improvement or a lower incidence of these behaviors over time. Knorth, Harder, Zandberg and Kendrick (2008) also concluded that after a period of residential care, on average children and youth improve their psychosocial functioning. More recently, Chow et al. (2014) have even 
Running head: The moderating role of length of stay in the relationship between cognitive dysregulation and peer attachment in adolescents living in residential care

revealed that group home placement might benefit some youth but not others, since boys showed improvements in protective skills and resources over time, whereas girls showed no differences over time in any areas of psychosocial functioning. As highlighted by the researchers, this may indicate that girls do not adapt as well as boys during group home care. Reviewing a significant amount of research, O'Neill (2008) also stated that while outcomes for boys and girls in residential care remain poor overall, there is evidence that they are worse for girls.

In many aspects, residential care has the potential to reduce the turbulence experienced by the adolescents and to promote positive experiences and trust in themselves, thus facilitating their formation of identity and social reintegration (Raymond, 1996). After all, for many of them the group home is the first place where they find the attention and the affection they need, and where they learn to think about their actions and the subsequent consequences in addition to the meaning of worth, effort and reward (Delgado, 2006). However, it is also true that the time spent in care along with placement disruptions can affect a youth's ability to establish pro-social friendships, which in turn could lead to fewer friends and more behavior problems (Farruggia \&

Germo, 2015). As stressed by Greger et al. (2016), placement disruptions contribute to a large number of broken relationships, making it especially difficult to maintain long-lasting friendships in out-of-home placed children and adolescents.

Youth in the Portuguese child welfare system tend to spend long periods of time in residential care. Considering the questions that remain open as to the potential benefits or disadvantages of longer stays in outof-home care and the undeniable impact that the new relationships formed in this context have in terms of the well-being of children under care, it becomes relevant to understand the role that length of placement plays in the processes that lead to the establishment of meaningful peer relationships. This would well represent critical information for those professionals who on a daily basis must arrive at decisions with both short- and long-term impact on the future of out-of-home placed children and youth, such as the review of protection measures in force every six months

Objectives

This study first aims to analyze the relationship between the emotional dysregulation of adolescents living in residential care and the attachment relationships they establish with peers and then to examine the moderating role which the length of stay in the group home may play in the association between these variables, for boys and girls separately. We hypothesize that emotional dysregulation of these adolescent boys and girls is 
Running head: The moderating role of length of stay in the relationship between cognitive dysregulation and peer attachment in adolescents living in residential care

negatively associated with their perception of attachment to peers. A second hypothesis is that length of stay in a residential setting has a moderating effect on the previous relationship, benefiting the attachment relationship with peers for both genders.

\section{Material and Methods}

\section{Participants}

The sample consists of 100 Portuguese adolescents ( 71 girls and 29 boys), aged between 12 and 18 years old $(\mathrm{M}=14.75$ and $\mathrm{SD}=1.88$ for the total sample; $\mathrm{M}=14.83$ and $\mathrm{SD}=2.00$ for boys $\mathrm{M}=14.72$ and $\mathrm{SD}$ $=1.85$ for girls), living in eight Infant and Juvenile Residential Group Homes ( 5 'only female' typology, 1 'only male' and 2 mixed) under the protection measure of extended placement in an institution. Of this sample, $35 \%$ of the adolescents had already been institutionalized before (55.2\% of the boys and $26.8 \%$ of the girls). The length of placement in the current institution ranges from 0 to 203 months $(M=42.99 ; S D=43.14)$, corresponding to 0 to 16 years. More than half of the adolescents $(59 \%)$ are in the present group home for less than 36 months.

Measures

\section{Emotional Dysregulation}

The Abbreviated Dysregulation Inventory (ADI; Mezzich, Tarter, Giancola \& Kirish, 2001; Portuguese version Petiz \& Rijo, 2011) is a 30-item self-report questionnaire, designed to assess psychological dysregulation in adolescents. It includes three subscales: Behavioral dysregulation (9 items), Cognitive dysregulation (10 items) and Affective dysregulation (11 items). Participants responded to the items using a 4point Likert scale ranging from 0 ("never true") to 3 ("always true"). The ADI was adapted for Portuguese adolescents by Motta, Rijo, Sousa, Pereira and Correia (in preparation), and has demonstrated good psychometric properties ( $\alpha=.87$ for Behavioral dysregulation, $\alpha=.73$ for Cognitive dysregulation and $\alpha=.83$ for Affective dysregulation). The same conclusion can be drawn for the present sample, given that Cronbach's $\alpha$ coefficients for the subscales (Cronbach, 1951) were .82, .83 and .86 for Behavioral, Cognitive and Affective dysregulation, respectively. The score for each subscale was calculated based on the average score of the corresponding items. 
Running head: The moderating role of length of stay in the relationship between cognitive dysregulation and peer attachment in adolescents living in residential care

Peer Attachment

Peer attachment was assessed using the Inventory of Parent and Peer Attachment (IPPA; Armsden \& Greenberg, 1987), translated and adapted for the Portuguese population by Neves (1995). Based on Bowlby's theoretical framework, this instrument performs a separate assessment of the adolescent's quality of attachment to their mother, father and friends, specifying the way in which these figures constitute sources of psychological security for the adolescents (Neves, Soares, \& Silva, 1999). In the present research, adolescents only responded to the friends scale. This scale consists of 25 items that encompass 3 factors: Communication (extension and quality of verbal communication), Trust (mutual understanding, respect and trust) and Alienation (feelings of alienation and isolation towards friends). Participants responded to the items on a 5 -point Likert scale, ranging from 1 ("never or almost never") to 5 (“always or almost always"). In the present study, internal consistency assessed by Cronbach's $\alpha$ was good for the global scale $(\alpha=.88)$ and for the subscales Communication $(\alpha=.82)$ and Trust $(\alpha=.87)$, and low $(\alpha=.55)$ for the subscale Alienation (Hair, Black, Babin, $\&$ Anderson, 2009). Since the internal consistency value for the Alienation subscale does not meet the criteria for acceptance, this subscale was excluded from data analysis. The final scores and those for each dimension were calculated based on the average score of the corresponding items.

\section{Demographics}

In order to better characterize the sample, the adolescents answered a brief socio-demographic questionnaire, containing data such as age, gender, number of placements, age at first placement and date of arrival at the present institution. Although many of the adolescents remembered factual information about their placement history, they were given the opportunity to check this information with the psychologists and social workers present when filling out the questionnaires that had access to their files.

\section{Procedure}

Nine residential care units from the Center Region of Portugal were contacted by telephone. A personal meeting was then arranged between the researcher and the institution's board in order to handle an authorization request communicating the research goals and to clarify any doubts. Only one unit did not respond to this request. Upon approval of the Boards of the other eight institutions, visits were scheduled for data collection. 
Running head: The moderating role of length of stay in the relationship between cognitive dysregulation and peer attachment in adolescents living in residential care

The aim of the study was first explained to the adolescents by the Psychologist of the Institution, who invited them to participate in this study. The exact number of refusals was not given to the researcher. For those who volunteered, the aims of the study were explained and all ethical procedures guaranteed, including anonymity and confidentiality. The protocol was applied, both individually and in group (no more than 5 elements at a time), depending on the availability of the adolescents at the moment and their difficulties in verbal comprehension and vocabulary knowledge. Given the characteristics of the sample, we first sought to foster some kind of relationship with the adolescents in order to better involve them in the process. Before the researcher received the completed questionnaires, the adolescents were asked to verify if all items had been answered properly thus resulting in no missings in the database. Adolescents with severe cognitive deficits were excluded from answering the questionnaires.

Data analysis

All analyses were performed with SPSS (v. 23, IBM SPSS). For all analyses a probability of a type I error of .05 was considered. The values of skewness and kurtosis were not far apart from the ones considered satisfactory for the assumption of normality (Kline, 2011), with values of $\mathrm{sk}<3$ and $\mathrm{ku}<8$. The effects size was interpreted considering Cohen's classification (2008). To understand whether the perception of attachment to peers could be predicted by emotional dysregulation, we conducted a multiple linear regression analysis with predictors being behavioral, cognitive and affective dysregulation, and criteria being attachment to peers, communication and trust. To determine whether length of stay could act as a moderator in the relationship between emotional dysregulation and attachment to peers, we performed a hierarchical regression analysis with standardized variables. We previously analyzed the assumptions of the model, namely the normal distribution, the homogeneity and the independence of errors. The first two assumptions were validated graphically and the independence assumption was validated with the Durbin-Watson statistic ( $d$ between 1 and 3). VIF was used to check for multicollinearity and none of the variables appear to be collinear (VIF <10; Tolerance $>0.2$ ).

Regression analyses were performed both for boys and girls. Age did not show statistically significant associations with criteria variables (see Table 1), which indicates no need for statistical control of this variable or for age group comparisons.

\section{Results}


Running head: The moderating role of length of stay in the relationship between cognitive dysregulation and peer attachment in adolescents living in residential care

Descriptive analyses

Pearson's coefficient was used to analyze the existence of correlations between emotional dysregulation, peer attachment and length of stay in the group home. The results of the correlations, as well as mean values and standard deviations for the total sample and for boys and girls are represented in Table 1.

Regarding the total sample, results showed that cognitive dysregulation is the only one that correlates with global peer attachment $(\mathrm{r}=-.305 ; p<.01)$, though moderately. Cognitive dysregulation also revealed a moderate correlation with communication $(\mathrm{r}=-.449 ; p<.01)$, and a weak one with trust $(\mathrm{r}=-.254 ; p<.05)$. All of these relationships were negative, indicating that the higher the cognitive dysregulation of the adolescents, the lower their perception of communication, trust and global attachment to peers.

These results showed some differences, however, when differentiated by gender. It was observed that in boys, cognitive dysregulation presents a moderate correlation with global peer attachment $(\mathrm{r}=-.499 ; p<.01)$ and a strong correlation with communication $(\mathrm{r}=-.622 ; p<.01)$ and trust $(\mathrm{r}=-.588 ; p<.01)$. Although a moderate association was found between cognitive dysregulation and communication in girls $(\mathrm{r}=-.348 ; p<.01)$, the same as no expression in global attachment to peers, meaning that for girls none of the dimensions of emotional dysregulation revealed any influence over attachment to peers. Therefore, the first hypothesis was only partially confirmed.

Results also showed strong correlations between behavioral and affective dysregulation $(\mathrm{r}=.627 ; p$ $<.01$ ), as well as between communication, trust, and global attachment, which suggests the way in which these variables are interconnected. Nonetheless, length of stay did not show any correlation with emotional dysregulation or peer attachment.

Predicting peer attachment from emotional dysregulation

As shown in Table 2, the general model consisting of behavioral, cognitive and affective dysregulation significantly predicted the adolescent's perception of attachment to peers in general $(p<.05)$, explaining $R^{2}=$ $12.6 \%$ of its variability in the total scale, $R^{2}=21.2 \%$ of communication with peers, and $R^{2}=8.7 \%$ of perceived trust. Of all the dimensions, cognitive dysregulation stood out once again as that which best accounts for the variability in perceived attachment to peers, in both the total scale and in communication and trust. 
Running head: The moderating role of length of stay in the relationship between cognitive dysregulation and peer attachment in adolescents living in residential care

It is, however, when analyzing the predictor role of emotional dysregulation over peer attachment by gender that the results showed greater significance. For instance, in boys, the general model consisting of the three dimensions of emotional dysregulation predicted $R^{2}=44.1 \%$ of global peer attachment, $R^{2}=53.7 \%$ of communication, and $R^{2}=53.09 \%$ of trust. Although in the case of global peer attachment and trust, all types of dysregulation seem to account for the variability of the data, whereas in communication only behavioral and cognitive dysregulation seem to explain the results found. On the other hand, results showed that in girls, the general model does not predict either global peer attachment or trust, but only communication $\left(R^{2}=12.5 \%\right)$. Of all the dimensions, cognitive dysregulation is the only one that best accounts for this result. 
Running head: The moderating role of length of stay in the relationship between cognitive dysregulation and peer attachment in adolescents living in residential care

Table 1 Inter-correlations between age, emotional dysregulation, peer attachment and length of stay, mean values and standard deviations in total sample $(N=100)$, in boys $(n=29)$ and in girls $(n=71)$

\begin{tabular}{|c|c|c|c|c|c|c|c|c|}
\hline Variables & $\mathrm{r}_{\text {age }}$ & 1 & 2 & 3 & 4 & 5 & 6 & 7 \\
\hline \multicolumn{9}{|l|}{ Emotional Dysregulation } \\
\hline \multicolumn{9}{|l|}{ 1. Behavioral } \\
\hline Boys & .233 & & & & & & & \\
\hline Girls & -.187 & - & & & & & & \\
\hline Total & -.068 & & & & & & & \\
\hline \multicolumn{9}{|l|}{ 2. Cognitive } \\
\hline Boys & -.103 & .117 & & & & & & \\
\hline Girls & .068 & .095 & - & & & & & \\
\hline Total & .009 & .091 & & & & & & \\
\hline \multicolumn{9}{|l|}{ 3. Affective } \\
\hline Boys & .177 & $.689^{* *}$ & -.044 & & & & & \\
\hline Girls & -.184 & $.590 * *$ & -.015 & - & & & & \\
\hline Total & -.068 & $.627 * *$ & -.039 & & & & & \\
\hline \multicolumn{9}{|l|}{ Peer Attachment } \\
\hline \multicolumn{9}{|l|}{ 4. Communication } \\
\hline Boys & -.053 & .231 & $-.622 * *$ & .072 & & & & \\
\hline Girls & -.017 & .072 & $-.348 * *$ & -.052 & - & & & \\
\hline Total & -.029 & .021 & $-.449 * *$ & -.008 & & & & \\
\hline \multicolumn{9}{|l|}{ 5. Trust } \\
\hline Boys & -.186 & -.072 & $-.588 * *$ & -.290 & $.791 * *$ & & & \\
\hline Girls & -.036 & .056 & -.117 & -.093 & $.780 * *$ & - & & \\
\hline Total & -.077 & -.041 & $-.254 *$ & -.116 & $.768^{* * *}$ & & & \\
\hline \multicolumn{9}{|l|}{ 6. Global scale } \\
\hline Boys & -.259 & -.034 & $-.499 * *$ & -.273 & $.858^{* * *}$ & $.925 * *$ & & \\
\hline Girls & -.024 & -.113 & -.209 & -.146 & $.879 * *$ & $.935 * *$ & - & \\
\hline Total & -.095 & -.092 & $-.305^{* * *}$ & -.161 & $.866 * *$ & $.931^{* * *}$ & & \\
\hline \multicolumn{9}{|l|}{ Demographic Variable } \\
\hline \multicolumn{9}{|c|}{ 7. Length of Stay (months) } \\
\hline Boys & & -.012 & -.240 & .069 & .025 & .015 & .056 & \\
\hline Girls & - & .007 & .046 & -.073 & .207 & .192 & .226 & - \\
\hline Total & - & .009 & -.049 & -.027 & .150 & .149 & .150 & \\
\hline M & & 7.76 & & & & & & \\
\hline Boys & 14.83 & 9.49 & 11.62 & 11.62 & 28.00 & 35.62 & 89.24 & 42.38 \\
\hline Girls & 14.72 & 8.99 & 10.75 & 14.92 & 28.04 & 37.73 & 92.27 & 43.24 \\
\hline Total & 14.75 & & 11.00 & 13.96 & 28.03 & 37.12 & 91.39 & 42.99 \\
\hline \multicolumn{9}{|l|}{ SD } \\
\hline Boys & 2.00 & 5.34 & 7.28 & 7.97 & 7.06 & 6.80 & 14.84 & 42.53 \\
\hline Girls & 1.85 & 5.63 & 5.69 & 6.92 & 6.11 & 8.42 & 15.57 & 43.69 \\
\hline Total & 1.88 & 5.58 & 6.17 & 7.36 & 6.37 & 8.01 & 15.35 & 43.14 \\
\hline
\end{tabular}


Running head: The moderating role of length of stay in the relationship between cognitive dysregulation and peer attachment in adolescents living in residential care

Table 2 Emotional dysregulation in the prediction of peer attachment, in the total sample $(N=100)$, in boys $(n$ =29) and in girls $(n=71)$

\begin{tabular}{|c|c|c|c|c|c|c|}
\hline Predictors & $\mathrm{R}$ & $\mathrm{R}^{2}$ & $\mathrm{R}^{2}$ adj & $F$ & $\beta$ & $\mathrm{t}$ \\
\hline \multicolumn{7}{|l|}{ General Model } \\
\hline Boys & .664 & 441 & .374 & $6.577^{* *}$ & \multirow{3}{*}{ - } & 19.672 \\
\hline Girls & .259 & .067 & .025 & 1.600 & & 18.407 \\
\hline Total & .356 & .126 & .099 & $4.632^{*}$ & & 25.112 \\
\hline \multicolumn{7}{|l|}{ Behavioral Dysregulation } \\
\hline Boys & \multirow{3}{*}{-} & \multirow{3}{*}{-} & \multirow{3}{*}{-} & \multirow{3}{*}{-} & .456 & $2.167^{*}$ \\
\hline Girls & & & & & -.038 & -.256 \\
\hline Total & & & & & .076 & .614 \\
\hline \multicolumn{7}{|l|}{ Cognitive Dysregulation } \\
\hline Boys & \multirow{3}{*}{-} & \multirow{3}{*}{-} & \multirow{3}{*}{-} & \multirow{3}{*}{-} & -.579 & $-3.790 * *$ \\
\hline Girls & & & & & -.207 & -1.739 \\
\hline Total & & & & & -.320 & $-3.320 * *$ \\
\hline \multicolumn{7}{|l|}{ Affective Dysregulation } \\
\hline Boys & \multirow{4}{*}{ - } & \multirow{3}{*}{ - } & & \multirow{3}{*}{-} & -.613 & $-2.926 * *$ \\
\hline Girls & & & - & & -.127 & -.867 \\
\hline \multirow[t]{2}{*}{ Total } & & & \multirow{2}{*}{\multicolumn{3}{|c|}{ Criteria: Communication }} & -1.793 \\
\hline & & & & & & \\
\hline Predictors & $\mathrm{R}$ & $\mathrm{R}^{2}$ & $R^{2}$ adj & $F$ & $\beta$ & $\mathrm{t}$ \\
\hline \multicolumn{7}{|l|}{ General Model } \\
\hline Boys & .733 & .537 & .482 & $9.670 * * *$ & & 14.416 \\
\hline Girls & .353 & .125 & .085 & $3.179 *$ & - & 15.335 \\
\hline Total & .461 & .212 & .188 & $8.616^{* * * *}$ & & 20.251 \\
\hline Behavioral Dysregulatio & & & & & & \\
\hline Boys & & & & & .542 & $2.829 * *$ \\
\hline Girls & & & & & -.007 & -.047 \\
\hline Total & - & - & - & - & .131 & 1.116 \\
\hline Cognitive Dysregulation & & & & & & \\
\hline Boys & & & & & -.700 & $-5.033 * * *$ \\
\hline Girls & - & - & - & - & -.348 & $-3.022 * *$ \\
\hline Total & & & & & -.465 & $-5.070 * * *$ \\
\hline Affective Dysregulation & & & & & & \\
\hline Boys & & & & & -.333 & -1.745 \\
\hline Girls & - & - & - & - & -.054 & -.377 \\
\hline Total & & & & & -.109 & -.927 \\
\hline & & & & eria: Trust & & \\
\hline $\begin{array}{r}\text { Predictors } \\
\end{array}$ & $\mathrm{R}$ & $\mathrm{R}^{2}$ & $R^{2}$ adj & $F$ & $\beta$ & $\mathrm{t}$ \\
\hline General Model & & & & & & \\
\hline Boys & .734 & .539 & .483 & $9.725^{* * * *}$ & & 19.851 \\
\hline Girls & .151 & .023 & -.021 & .520 & - & 13.241 \\
\hline Total & .294 & .087 & .058 & $3.038^{*}$ & & 19.114 \\
\hline Behavioral Dysregulatio & & & & & & \\
\hline Boys & & & & & .431 & $2.249 *$ \\
\hline Girls & - & - & - & - & .017 & .115 \\
\hline Total & & & & & -.103 & .813 \\
\hline Cognitive Dysregulation & & & & & & \\
\hline Boys & & & & & -.665 & $-4.788^{* * * *}$ \\
\hline Girls & - & - & - & - & -.120 & -.985 \\
\hline Total & & & & & -.271 & $-2.745^{* *}$ \\
\hline Affective Dysregulation & & & & & & \\
\hline Boys & & & & & -.616 & $-3.236 * *$ \\
\hline Girls & - & - & - & - & -.105 & -.697 \\
\hline Total & & & & & -.191 & 1.512 \\
\hline
\end{tabular}

Note. Standardized Coefficients $(\beta), \mathrm{t}$ value $(\mathrm{t})$ and significance $(p): * p<0.05, * * p<0.01, * * * p<0.001$ 
Running head: The moderating role of length of stay in the relationship between cognitive dysregulation and peer attachment in adolescents living in residential care

The moderating effect of length of stay in the relationship between emotional dysregulation and peer attachment

We tested the moderating effect of length of stay in the relationship between emotional dysregulation and peer attachment (see Table 3, only moderator effect was shown for boys, girls, and total sample). Given the associations between cognitive dysregulation and communication, trust and the global scale, we used cognitive dysregulation and length of stay as independent variables (z scores), and peer attachment (global scale, communication, and trust) as dependent variables, separately analyzed. To test the moderating effect, we added to the regression model the product of the two standardized independent variables.

Although the interaction effect did not reveal statistical significance in the total sample, analyses by gender showed a significant effect in boys. According to the results, length of stay in the group home moderates the relationship between cognitive dysregulation and global peer attachment, the model $R^{2}=44.7 \%$ of the variability of peer attachment. The relationship between cognitive dysregulation and communication with peers was equally moderated by length of stay. This model explained $R^{2}=55.5 \%$ of the variability of communication with peers.

Finally, results also showed a significant interaction between length of stay and cognitive dysregulation in the prediction of trust in peers, explaining $R^{2}=46.7 \%$ of its variability. 
Running head: The moderating role of length of stay in the relationship between cognitive dysregulation and peer attachment in adolescents living in residential care

Table 3 Interaction between length of stay and emotional dysregulation in the prediction of peer attachment, in the total sample $(N=100)$, in boys $(n=29)$ and in girls $(n=71)$

\begin{tabular}{|c|c|c|c|c|c|c|c|}
\hline \multirow[b]{2}{*}{ Predictors } & \multirow[b]{2}{*}{$\mathrm{R}$} & \multicolumn{6}{|c|}{ Peer Attachment (Global) } \\
\hline & & $\mathrm{R}^{2}$ & $R^{2}$ adj & $\Delta \mathrm{R}^{2}$ & $F$ & $\beta$ & $\mathrm{t}$ \\
\hline \multicolumn{8}{|c|}{ Behavioral Dysregulation $\mathrm{X}$} \\
\hline \multicolumn{8}{|c|}{ Length of stay } \\
\hline Boys & .068 & .005 & -.115 & - & .039 & -.020 & -.098 \\
\hline Girls & .264 & .069 & .028 & - & 1.668 & -.019 & -.156 \\
\hline Total & .177 & .031 & .001 & - & 1.036 & -.013 & -.125 \\
\hline \multicolumn{8}{|c|}{ Cognitive Dysregulation $\mathrm{X}$} \\
\hline \multicolumn{8}{|c|}{ Length of stay } \\
\hline Boys & .669 & .447 & .381 & .165 & $6.738^{*}$ & .407 & 2.733 \\
\hline Girls & .373 & .139 & .100 & .040 & 3.605 & -.200 & -1.757 \\
\hline Total & .334 & .112 & .084 & - & 4.027 & -.022 & -.232 \\
\hline \multicolumn{8}{|c|}{ Affective Dysregulation X } \\
\hline \multicolumn{8}{|c|}{ Length of stay } \\
\hline Boys & .277 & .077 & -.304 & .001 & .691 & .026 & .131 \\
\hline Girls & .264 & .070 & .028 & .002 & 1.675 & -.041 & -.347 \\
\hline \multirow[t]{2}{*}{ Total } & .218 & .047 & .018 & - & 1.595 & -.015 & -.151 \\
\hline & & \multicolumn{6}{|c|}{ Communication } \\
\hline Predictors & $\mathrm{R}$ & $\mathrm{R}^{2}$ & $R^{2}$ adj & $\Delta \mathrm{R}^{2}$ & $F$ & $\beta$ & $\mathrm{t}$ \\
\hline \multicolumn{8}{|c|}{ Behavioral Dysregulation X } \\
\hline \multicolumn{8}{|c|}{ Length of stay } \\
\hline Boys & .235 & .055 & -.058 & .001 & .487 & -.036 & -.179 \\
\hline Girls & .222 & .049 & .007 & .001 & 1.153 & -.030 & -.245 \\
\hline Total & .156 & .024 & -.006 & .001 & .796 & -.036 & -.355 \\
\hline \multicolumn{8}{|c|}{ Cognitive Dysregulation X } \\
\hline \multicolumn{8}{|c|}{ Length of stay } \\
\hline Boys & .745 & .555 & .502 & .152 & $10.390 * *$ & .390 & 2.919 \\
\hline Girls & .440 & .194 & .158 & .023 & 5.374 & -.152 & -1.374 \\
\hline Total & .467 & .218 & .194 & - & 8.924 & .017 & .187 \\
\hline \multicolumn{8}{|c|}{ Affective Dysregulation X } \\
\hline \multicolumn{8}{|c|}{ Length of stay } \\
\hline Boys & .078 & .006 & -.113 & .001 & .051 & -.024 & -.116 \\
\hline Girls & .220 & .048 & .006 & .004 & 1.133 & -.064 & -.529 \\
\hline \multirow[t]{2}{*}{ Total } & .157 & .025 & -.006 & .002 & .806 & -.044 & -.438 \\
\hline & & \multicolumn{6}{|c|}{ Trust } \\
\hline $\begin{array}{r}\text { Predictors } \\
\end{array}$ & $\mathrm{R}$ & $\mathrm{R}^{2}$ & $R^{2}$ adj & $\Delta \mathrm{R}^{2}$ & $F$ & $\beta$ & $\mathrm{t}$ \\
\hline \multicolumn{8}{|c|}{ Behavioral Dysregulation X } \\
\hline Length of stay & & & & & & & \\
\hline Boys & .073 & .005 & -.114 & - & .045 & .003 & .014 \\
\hline Girls & .212 & .045 & .002 & .005 & 1.050 & -.070 & -.579 \\
\hline Total & .164 & .027 & -.004 & .003 & .882 & -.502 & -.515 \\
\hline Cognitive Dysregulati & & & & & & & \\
\hline Length of stay & & & & & & & \\
\hline Boys & .683 & .467 & .403 & .105 & $7.292 *$ & .324 & 2.214 \\
\hline Girls & .301 & .091 & .050 & .038 & 2.228 & -.196 & -1.674 \\
\hline Total & .293 & .086 & .057 & .002 & 3.004 & -.049 & -.504 \\
\hline Affective Dysregulatic & & & & & & & \\
\hline Length of stay & & & & & & & \\
\hline Boys & .331 & .110 & .003 & .024 & 1.025 & .158 & .823 \\
\hline Girls & .225 & .051 & .008 & .008 & 1.192 & -.088 & -.732 \\
\hline Total & .189 & .036 & .006 & .001 & 1.186 & -.031 & -.309 \\
\hline
\end{tabular}

Note. Standardized Coefficients $(\beta), \mathrm{t}$ value $(\mathrm{t})$ and significance $(p)$ : $* p<0.05, * * p<0.01, * * * p<0.001$

The interaction effects were graphically represented through ModGraph (Jose, 2013) (see Figures 1 to $3)$. 
Running head: The moderating role of length of stay in the relationship between cognitive dysregulation and peer attachment in adolescents living in residential care

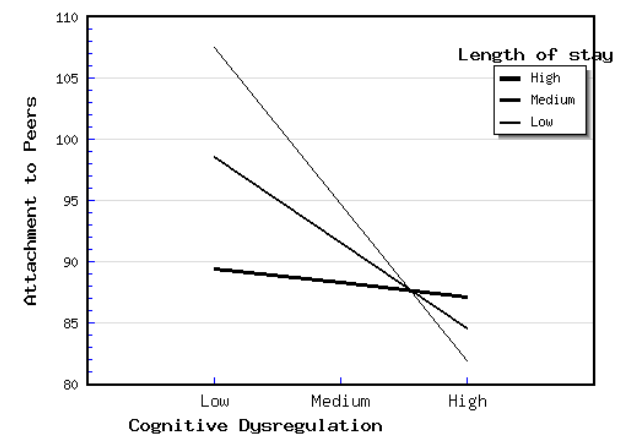

Figure 1. The moderating effect of length of stay in the relationship between cognitive dysregulation and peer attachment in boys

Figure 1 reveals that when the adolescents' cognitive dysregulation is low, the higher the length of stay in the group home the lower the perception of attachment to peers. On the contrary, when the level of cognitive dysregulation is high, adolescents institutionalized for a longer period of time showed a higher perception of attachment to peers when compared with the ones that are institutionalized for a shorter period. Also, when institutionalized for a long period of time, the level of an adolescents' cognitive dysregulation does not seem to significantly affect their attachment to peers.

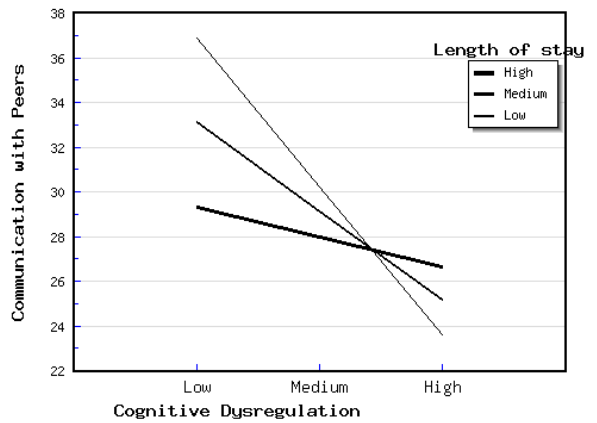

Figure 2. The moderating effect of length of stay in the relationship between cognitive dysregulation and communication with peers in boys

Figure 2 shows that when the adolescents' cognitive dysregulation is low, the higher the length of stay in the group home, the less the boys communicate with peers. However, as the levels of dysregulation increase, communication with peers tends to grow for the adolescents who are institutionalized for longer periods of time. 
Running head: The moderating role of length of stay in the relationship between cognitive dysregulation and peer attachment in adolescents living in residential care

As such, length of stay appears to have a buffer effect on communication with peers only in adolescents with higher cognitive dysregulation.

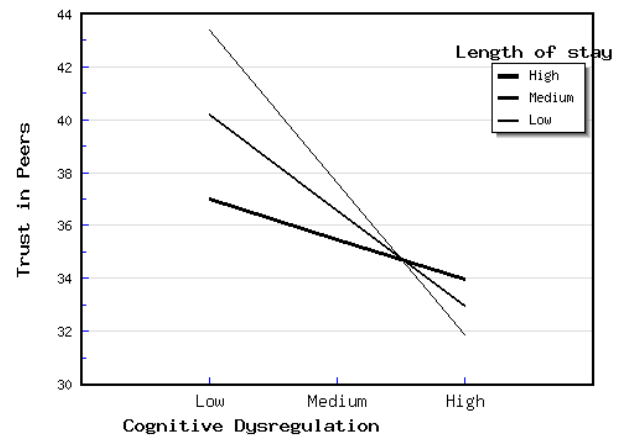

Figure 3. The moderating effect of length of stay in the relationship between cognitive dysregulation and trust in peers in boys

Figure 3 also shows the same type of influence of length of stay in the interaction between cognitive dysregulation and trust in peers. That means that as cognitive dysregulation presented by the adolescents grows higher, trust in peers seems to increase for adolescents who are institutionalized for a longer period of time. In adolescents who have been institutionalized for a shorter period of time, lower levels of cognitive dysregulation corresponded to a higher trust in peers.

In light of these results, the second hypothesis was only partially confirmed, since length of stay in the group home only has a moderating effect for boys.

\section{Discussion}

Given the well-established importance of peer relationships to the psychosocial development of adolescents, particularly the ones who live in group homes, the present study first sought to analyze how the emotional dysregulation of adolescents living in residential care interferes with the quality of the relationships they establish with their peers. Results revealed that dysregulation (behavioral, cognitive and affective) significantly predicts these adolescents' perception of attachment to peers, especially regarding communication with them. Of all the considered dimensions of dysregulation, cognitive dysregulation was the only one that showed a significant correlation with peer attachment - in general, in communication and in trust - standing out equally as the dimension that best accounts for each one of these variables. This data is convergent with what 
Running head: The moderating role of length of stay in the relationship between cognitive dysregulation and peer attachment in adolescents living in residential care

several theories about emotional regulation describe when highlighting the importance of cognition in the control of the behavioral expression of affection (Garnefski, Kraaij, \& Spinhoven, 2001; Thompson, 1994 2011). In particular, studies with mistreated children have noted how difficult it is for them to understand negative affection and to control it adaptively in a dynamic in which cognitive control acts as a partial mediator of the effects of maltreatment on the effectiveness of social interactions (Rogosch, Cicchetti, \& Aber, 1995) Since the development of intimate relationships with peers is moderated by the cognitive development of the adolescents (Berndt, 1982), the results of this study suggest that the higher the cognitive dysregulation of institutionalized adolescents, the less they perceive themselves as being able to trust and communicate with their peers, as well as to establish close bonds with them.

Nevertheless, when analysed by gender, results were quite different. Even though cognitive dysregulation in boys correlated similarly with each of the dimensions of peer attachment, the same was not observed in girls for whom only cognitive dysregulation presented a significant correlation with communication.

In boys, dysregulation (behavioral, cognitive and affective) maintained the same predictive value it had in the total sample. For them, all the dimensions of dysregulation seem to explain, though differently, global attachment to peers and trust. As for communication, only behavioral and cognitive dysregulation emerge as the variables that better explain the results found. Curiously enough, for institutionalized male adolescents, higher levels of behavioral dysregulation predicted higher attachment to peers, as well as higher trust and communication. A possible explanation for these findings may rest in the fact that boys tend to exhibit higher externalization problems (Rescorla et al., 2007) which, in a context where behavioral problems are recurrent and often the reason why they are in residential care, can act as an element of interpersonal identification and, therefore, as a bonding agent, thus facilitating the development of significant relationships with peers.

As previously mentioned, in girls the general model consisting of the three dimensions of dysregulation only predicted communication with peers in a significant manner, particularly cognitive dysregulation. Data on the normative development suggest that trust and honesty are fundamental to the success of interpersonal relationships (Rotenberg, 2010), and that girls are more suspicious and selective when expressing their affections (Derks, Lee, \& Krabbendam, 2014). Since these girls' previous interpersonal experiences were characterized by insecurity and distrust, their predisposition to developing new interpersonal relationships is conditioned by those same experiences, which results, hypothetically, in a lower willingness to attach to peers in the context they were fostered and to develop communication patterns based on mutual understanding and consideration for the opinions of others. Also, the fact that the sub-sample of girls is larger than the sub-sample 
Running head: The moderating role of length of stay in the relationship between cognitive dysregulation and peer attachment in adolescents living in residential care

of boys is not negligible, which can contribute to diluting the possible associations between variables.

Secondly, an analysis was made of the moderating role of length of stay in the group home in the relationship between cognitive dysregulation and peer attachment. In the analysis performed for both genders, findings revealed that length of stay only moderates the relationship between cognitive dysregulation and communication, trust and global attachment to peers in boys. However, the influence of length of stay on the adolescents' connection to their peers varies depending on the levels of cognitive dysregulation they present. Therefore, for boys who have a higher cognitive dysregulation, staying longer in the group home favors greater communication, trust and perception of attachment to peers. These results strengthen the positive influence of length of stay in residential care, as shown by other studies (Lee \& Thompson, 2009; Knorth, Harder, Zandberg, \& Kendrick, 2008; Ringle, Ingram, \& Thompson, 2010; Thompson et al.,1996), making it important to enlighten which conditions of group home life tend to support this effect and promote changes that are favorable to an adaptive functioning of adolescents in out-of-home care.

Gender differences were also mirrored in the moderating analysis; however, what is needed is an explanation of why the moderating effect only emerges for boys. Similar and previous to this study, Chamberlain and Reid (1994) also reported findings which indicate that although girls may exhibit fewer behavioral problems when they begin residential care, their frequency tends to increase over time, whereas boys seem to exhibit more disruptive behaviors at the beginning which, in turn, tend to decrease consistently through care. Taking into account the behavioral problems of institutionalized girls, studies showed that their levels of externalizing behaviors are similar to that of boys (Handwerk et al., 2006). They simultaneously reported higher scores in behavioral and emotional problems when compared to boys, exhibiting higher rates of internalizing psychopathology (Connor, Doerfler, Toscano, Volungi,s \& Steingard, 2004; Handwerk et al., 2006; Weis, Whitemarsh, \& Wilson, 2005). In a study that intended to analyze autonomy, self-esteem and educational plans in a comparative sample of institutionalized and non-institutionalized adolescents, Tulviste (2011) also showed that institutionalized boys tend to demonstrate greater emotional autonomy than girls when in the same circumstances.

The intensity and interconnection of boys' social networks when compared to that of girls (Rose \& Smith, 2009), in addition to the evidence of higher rates of psychopathology for girls, might partially explain why length of stay in the group home only displayed favorable outcomes for boys. However, despite the advanced explanatory hypotheses, the findings of this study need to be validated with more research that will serve to confirm the extent to which boys and girls in residential care handle this experience very differently. It 
Running head: The moderating role of length of stay in the relationship between cognitive dysregulation and peer attachment in adolescents living in residential care

would also be important to understand the different strategies these boys and girls employ to cope with the reality of living in a group home.

Implications for Practice

Over time, institutionalization has been seen as a condition of deprivation involving multiple deficits in the physical, emotional and social development of children and youth at risk. Nevertheless, Rushton and Minnis (2008) draw attention to the repercussions of attempting to validate classical studies for the present day. The results here obtained represent a contribution to a positive perspective on long-term residential care, given that a longer length of stay in the group home seems to benefit boys, in particular when they are more emotionally dysregulated. The advantages that emerge from this circumstance are mirrored in the interpersonal relationships established, especially with peers.

Comparable to what happens with primary caregivers in the first years, friendships are seen to have a modulating role in the adolescents' emotional experiences, given that they feel the need to look to peers for information about how to respond to social and emotional situations (Steinberg \& Silk, 2002) or how to handle emergent problems such as sexuality, independence and intimacy (Morris et al., 2007). That is why it is necessary to promote residential care practices that foster and reinforce positive interactions with peers.

Although today's notion of institutionalization does not portray a context of severe neglect, the findings of this study strengthen the need to invest even more in the quality of care in the residential context, since it has already proved to be a major precursor of adolescent well-being (e.g. Ahrens et al., 2011; Mota \& Matos, 2015;

Schneiderman, Smith \& Palinkas, 2012). Once the differences that underlie the adaptation processes of boys and girls to residential care are known, it will be possible to define more specific and effective intervention strategies, with a higher probability of providing successful care experiences.

Limitations and Future Directions

The main limitation of this study concerns the sample size, which is in part related to the difficulty of access to the group homes. Also, the higher number of girls in the sample can be a possible explanation for the differential results that have been found between both genders of institutionalized adolescents. Yet despite these limitations, the results of the present study pave the way for new research paths with regard to the 
Running head: The moderating role of length of stay in the relationship between cognitive dysregulation and peer attachment in adolescents living in residential care

institutionalization of youth at risk. As such, it would be interesting to study the differences found between genders in greater detail, as well as to monitor the development of the adolescents who live in residential group homes over time, examining the way the quality of the care and the length of stay can both contribute to the persistence or to the improvement of the emotional and social difficulties caused by experiences of maltreatment.

\section{Conclusion}

The present study highlighted the role of length of stay as a moderating variable in the association between emotional dysregulation and peer attachment in adolescent boys living in a residential care context. The need for more research on the impact of care procedures and other characteristics of the group home over time is underscored, along with the need to continuously promote positive interactions with peers in these contexts. Results also stress the need to develop specific interventions in residential care contexts that can focus on specific groups, as in the case of boys and girls.

\section{References}

Ahrens, K. R., DuBois, D. L., Garrison, M., Spencer, R. Richardson, L. P., \& Lozano, P. (2011). Qualitative exploration of relationships with important non-parental adults in the lives of youth in foster care. Children and Youth Services Review, 33, 1012-1023. doi: 10.1016/j.childyouth.2011.01.006.

Anglin, J. P. (2002). Pain, normality and the struggle for congruence: Reinterpreting residential care for children and youth. New York: Routledge.

Armsden, G., \& Greenberg, M. (1987). The inventory of parent and peer attachment: Individual differences and their relationship to psychological well-being in adolescence. Journal of Youth and Adolescence, 16 (5), 427-454. doi: 10.1007/BF02202939.

Barter, C. (2003). Young people in residential care talk about peer violence. Scottish Journal of Residential

Child Care, 2 (2), 39-50. Retrieved from http://www.sircc.org.uk/sites/default/files/Peer_Violence.pdf.

Barter, C. (2008). Prioritizing young people's concerns in residential care: Responding to peer violence. In A.

Kendrick (ed.), Residential child care: Prospects and challenges (pp. 137-151). London: Jessica Kingsley.

Berndt, T. J. (1982). The features and affects of friendship in early adolescence. Child Development, 53, $1447-$

1460. doi: $10.2307 / 1130071$ 
Running head: The moderating role of length of stay in the relationship between cognitive dysregulation and peer attachment in adolescents living in residential care

Browne, K., Hamilton-Giachritsis, C., Johnson, R. \& Ostergren, M. (2006). Overuse of institutional care for children in Europe. BMJ, 332 (7539), 485-487. doi: 10.1136/bmj.332.7539.485

Cicchetti, D., \& Toth, S. L. (2005). Child maltreatment. Annual Review of Clinical Psychology, 1, 409-438. doi: 10.1146/annurev.clinpsy.1.102803.144029.

Chamberlain, P. \& Reid, J. B. (1994). Differences in risk factors and adjustment for male and female delinquents in treatment foster care. Journal of Child and Family Studies, 3 (1), 23-39. doi: 10.1007/BF02233909.

Chow, W., Mettrick, J. E., Stephan, S. H. \& Von Waldner, C. A. (2014). Youth in group home care: Youth characteristic and predictors of later functioning. Journal of Behavioral Health Services \& Research, 41(4), 503-519. doi: 10.1007/s11414-012-9282-2.

Cohen, B. (2008). Explaining psychological statistics. New Jersey: Hoboken.

Connor, D. F., Doerfler, L. A., Toscano, P. F., Volungis, A., \& Steingard, R. J. (2004). Characteristics of children and adolescents admitted to a residential treatment center. Journal of Child and Family Studies, 13 (4), 497-510. doi: 10.1023/B:JCFS.0000044730.66750.57.

Cook, A., Spinazzola, J. Ford, J., Lanktree, C., Blaustein, M., Cloitre, M., ... van der Kolk, B. (2005). Complex trauma in children and adolescents. Psychiatric Annals, 35 (5), 390-398. Retrieved from https://nursebuddha.files.wordpress.com/2011/12/complex-trauma-in-children.pdf.

Crittenden, P. M. (1992). Quality of attachment in the preschool years. Development and Psychopathology, 4 (2), 209-241. doi: 10.1017/S0954579400000110.

Cronbach, L. J. (1951). Coefficient Alpha and the internal structure of tests. Psychometrika, 6 (13), 297-334.

Delgado, P. (2006). Os direitos da Criança: da participação à responsabilidade. O sistema de proteção e educação das Crianças e Jovens. Porto: Profedições.

Derks, J., Lee, N. C., \& Krabbendam, L. (2014). Adolescent trust and trustworthiness: Role of gender and social value orientation. Journal of Adolescence, 37 (8), 1379-1386. doi: 10.1016/j.adolescence.2014.09.014.

Emond, R. (2003). Putting the care into residential care: The role of young people. Journal of Social Work, 3 (3), 321-337. doi: 10.1177/146801730333004.

Emond, R. (2014). Longing to belong: Children in residential care and their experiences of peer relationships at school and in children's home. Child and Family Social Work, 19(2), 194-202. doi:10.1111/j.13652206.2012.00893.x 
Farrugia, S. P. \& Germo, G. R. (2015). Problem behavior among older youth in foster care: Examining gender. Children and Youth Services Review, 48, 20-30. doi: 10.1016/j.childyouth.2014.11.005.

Fernández-Molina, M., del Valle, J., Fuentes, M. J., Bernedo, I. M. \& Bravo, A. (2011). Problemas de conducta de los adolescentes en acogimiento preadoptivo, residencial y com família extensa [Behavioural problems in adolescents who are in adoption, residential care, and grandparent fostering]. Psicothema, 23(1), 1-6.

Fett, A. J., Shergill, S. S., Gromann, P. M., Dumontheil, I., Blakemore, S., Yakub, F., \& Krabbendam, L. (2014). Trust and social reciprocity in adolescence - A matter of perspective taking. Journal of Adolescence, 37(2), 175-184. doi: 10.1016/j.adolescence.2013.11.011.

Garnefsky, N., Kraaij, V., \& Spinhoven, P. (2001). Negative life events, cognitive emotion regulation and emotional problems. Personality and Individual Differences, 30, 1311-1327. doi: 10.1016/S01918869(00)00113-6.

Goldstein, J, Solnit, A., Goldstein, S. \& Freud, A. (1996). The Best Interests of the Child. The Least Detrimental Alternative. NY: The Free Press

Gorrese, A., \& Ruggieri, R. (2012). Peer attachment: A meta-analytic review of gender and age differences and associations with parent attachment. Journal of Youth and Adolescence, 41, 650-672. doi: 10.1007/s10964-012-9759-6.

Greger, H. K., Myhre, A. K., Lydersen, S. \& Josefiak, T. (2015). Previous maltreatment and present mental health in a high-risk adolescent population. Child Abuse \& Neglect, 45, 122-134. doi: 10.1016/j.chiabu.2015.05.003.

Greger, H. K., Myhre, A. K., Lydersen, S. \& Josefiak, T. (2016). Child maltreatment and quality of life: a study of adolescents in residential care. Health and Quality of Life Outcomes, 14(74), 1-17. doi: 10.1186/s12955016-0479-6

Gwynn, C., Meyer, R., \& Schaefer, C. (1993). The influence of the peer culture in residential treatment. In C. Schaefer \& A. Swanson (Eds), Children in residential care: Critical issues in treatment (2 ${ }^{\mathrm{a}}$ ed., pp. 104133). Northvale, N.J.: Jason Aronson Inc.

Hair, J. F., Black, W. C., Babin, B. J., \& Anderson, R. E. (2009). Multivariate data analysis (7 ${ }^{\text {th }}$ ed.). NJ: Prentice-Hall.

Handwerk, M. L., Clopton, K., Huefner, J. C., Smith, G. L., Hoff, K. E., \& Lucas, C. P. (2006). Gender differences in adolescents in residential treatment. American Journal of Orthopsychiatry, 76 (3), $312-$ 324. doi: 10.1037/0002-9432.76.3.312. 
Running head: The moderating role of length of stay in the relationship between cognitive

Instituto da Segurança Social, I.P. (2016). CASA 2015 - Relatório de caracterização anual da situação de acolhimento das crianças e jovens [CASA 2015 - Annual characterization report of the out-of-home placement of children and adolescents]. Retrieved from http://www.segsocial.pt/documents/10152/14725795/Relat\%C3\%B3rio_CASA_2015/f3e06877-ad73-48e4-8395$75 \mathrm{~b} 33$ fedcae 0

Jose, P. E. (2013). Moderation/Mediation Help Centre. Victoria University of Wellington, Wellington, New Zealand, School of Psychology.

Kline, R. B. (2011). Principles and Practice of Structural Equation Modeling ( ${ }^{\text {rd }}$ ed). New York: The Guilford Press.

Knorth, E. J., Harder, A. T., Zandberg, T. \& Kendrick, A. J. (2008). Under one roof: A review and selective meta-analysis on the outcomes of residential child and youth care. Children and Youth Services Review 30, 123-140. doi: 10.1016/j.childyouth.2007.09.001.

Lázaro, S. \& López, F. (2010). Continuidad de los efectos del amltrato durante la infância en adolescentes acogidos en centros de protección [Continuity of the effects of maltreatment during childhood in adolescents in residential care]. Infancia y Aprendizage, 33(2), 255-268. doi: $10.1174 / 021037010791114599$.

Lee, B. R., \& Thompson, R. (2009). Examining externalizing behavior trajectories of youth in group homes: Is there evidence for peer contagion? Journal of Abnormal Child Psychology, 37, 31-44. doi: $10.1007 / \mathrm{s} 10802-008-9254-4$.

MacLean, K. (2003). The impact of institutionalization on child development. Development and Psychopathology, 3, 853-884. doi: 10.1017.S0954579403000415.

Mezzich, A., Tarter, R., Giancola, P., \& Kirisci, L. (2001). The dysregulation inventory: A new scale to access the risk for substance use disorder. Journal of Child and Adolescent Substance Abuse, 10 (4), 35-43. doi: 10.1300/J029v10n04_04.

Monks, C. P., Smith, P. K., Naylor, P., Ireland, J. L. \& Coyne, I. (2009). Bullying in different contexts:

Commonalities, differences and the role of theory. Aggression and Violent Behavior, 14(2), 146-156. doi: 10.1016/j.avb.2009.01.004.

Morgan, R. (2009). Life in Children's Homes: A report of children's experience. Manchester: Ofsted. 
Morris, A. S., Silk, J. S., Steinberg, L., Myers, S. S., \& Robinson, L. R. (2007). The role of the family context in the development of emotion regulation. Social Development, 16 (2), 361-388. doi:10.1111/j.1467-95072007.00389.x.

Mota, C. P. \& Matos, P. M. (2010). Adolescentes institucionalizados: O papel das figuras significativas na predição da assertividade, empatia e autocontrolo [Institutionalized adolescents: The role of significant figures in the prediction of assertiveness, empathy and self-control]. Análise Psicológica, 2 (28), 245-254. doi: 10.14417/ap.278.

Mota, C. P., \& Matos, P. M. (2015). Adolescents in institutional care: Significant adults, resilience, and wellbeing. Child and Youth Care Forum, 44, 209-224. doi: 10.1007/s10566-014-9278-6.

Motta, C., Rijo, D., Sousa, B., Pereira, M. \& Correia, L.. The Abbreviated Dysregulation Inventory: Dimensionality and psychometric properties. Manuscript in preparation.

Neves, L. (1995). Suporte emocional na adolescência: a relação com os pais e com os amigos em momentos de transição escolar. [Emotional support in adolescence: the relationship with parents and friends during school transition] (Unpublished master dissertation). Faculty of Psychology and Educational Sciences: Coimbra.

Neves, L., Soares, I. \& Silva, M. C. (1999). Inventário da Vinculação na Adolescência - I.P.P.A [The

Attachment Inventory in Adolescence - I.P.P.A.]. In M. Simões, M. Gonçalves \& L. Almeida (Eds.),

Testes e Provas Psicológicas em Portugal - Vol. 2 (p.37-48). Braga: Sistemas Humanos e Organizacionais, Lda.

Nobre-Lima, L. (2009). Estórias e projetos de vida de adolescentes institucionalizados [Stories and life projects of institutionalized adolescents] (Unpublished doctoral dissertation). Faculty of Psychology and Educational Sciences: Coimbra.

O’Neill, T. (2008). Gender matters in residential child care. In Kendrick, A. (ed). Residential Child Care: Prospects and Challenges. London: Jessica Kingsley.

Pereira, M., Soares, I., Dias, P., Silva, J., Marques, S., \& Baptista, J. (2010). Desenvolvimento, psicopatologia e apego: Estudo exploratório com crianças institucionalizadas e suas cuidadoras [Development, psychopathology and attachment: An exploratory study with institutionalized children and their caregivers]. Psicologia: Reflexão e Crítica, 23 (2), 222-231. Retrieved from http://www.scielo.br/pdf/prc/v23n2/v23n2a04.pdf. 
Raymond, M. (1996). Reflexões sobre o acompanhamento em instituição de adolescentes difíceis

[Considerations about the monitorization of difficult adolescents in the institution]. Infância e Juventude, 3, 591-609.

Rescorla, L., Achenbach, T., Ivanova, M. Y., Dumenci, L., Almqvist, F., Bilenberg, N., ... Verhulst, F. (2007). Behavioral and emotional problems reported by parents of children ages 6 to 16 in 31 societies. Journal of Emotional and Behavioral Disorders, 15 (3), 130-142. doi: 10.1177/10634266070150030101.

Ringle, J. L., Ingram, S. D., \& Thompson, R. W. (2010). The association between length of stay in residential care and educational achievement: Results from 5- and 16-year follow-up studies. Children and Youth Services Review, 32, 974-980. doi: 10.1016/j.childyouth.2010.03.022.

Rogosch, F. A., Cicchetti, D., \& Aber, J. L. (1995). The role of child maltreatment in early deviations in cognitive and affective processing abilities and later peer relationship problems. Development and Psychopathology, 7 (4), 591-609. doi: 10.1017/S0954579400006738.

Rose, A. J., \& Rudolph, K. D. (2006). A review of sex differences in peer relationship processes: Potential trade-offs for the emotional and behavioural development of girls and boys. Psychological Bulletin, 132(1), 98-131. doi: 10.1037/0033-2909.132.1.98.

Rose, A. J., \& Smith, R. L. (2009). Sex diferences in peer relationships. In K. H. Rubin, W. M. Bukowski \& B.

Laursen (Eds.), Handbook of peer interactions, relationships, and groups (pp. 379-393). New York: Guilford Press.

Rotenberg, K. J. (2010). The conceptualization of interpersonal trust: a basis, domain and target framework. In

K. J. Rotenberg (Eds.), Interpersonal trust during childhood and adolescence. (pp. 8-27). University of Keele: Cambridge University Press.

Rotenberg, K. J. \& Boulton, M. (2013). Interpersonal trust consistency and the quality of peer relationships during childhood. Social Development, 22(2), 225-241. doi: 10.1111/sode.12005.

Rushton, A., \& Minnis, H. (2008). Residential and foster family care. In M. Rutter, D. Bishop, D. Pine, S. Scott,

J. Stevenson, E. Taylor, \& A. Thapar (Eds), Rutter's child and adolescent psychiatry (5 ${ }^{\text {th }}$ ed., pp. 487-501). Malden, Massachusetts: Blackwell Publishing.

Ryan, J. P., Marshall, J. M., Herz, D. \& Hernandez, P. M. (2008). Juvenile delinquency in child welfare: Investigating group home effects. Children and Youth Services Review, 30, 1088-1099. doi: 10.1016/j.childyouth.2008.02.004. 
Schneiderman, J. U., Smith, C., \& Palinkas, L. A. (2012). The caregiver gatekeeper for accessing health care for children in foster care: A qualitative study of kinship and unrelated caregivers. Children and Youth Services Review, 34, 2123-2130. doi: 10.1016/j.childyouth. 2012.07.009.

Shaw, J. (2014). Why do young people offend in children's homes? Research, theory and practice. British Journal of Social Work, 44 (7), 1823-1839. doi: 10.1093/bjsw/bct047.

Shaw, J., \& Frost, N. (2013). Young people and the care experience: Research, policy and practice. New York: Routhledge.

Shields, A., \& Cicchetti, D. (2001). Parental maltreatment and emotion dysregulation as risk factors for bullying and victimization in middle childhood. Journal of Clinical Child Psychology, 30, 349-363. doi: 10.1207/S15374424JCCP3003_7.

Soares, I., Silva, J., Marques, S., Baptista, J., \& Oliveira, A. (2010). Uma perspectiva desenvolvimental sobre o impacto da institucionalização e da adopção em crianças. [A developmental perspective over the impact of institutionalization and adoption on children] In C. Machado (Coord.), Vitimologia: Das novas abordagens teóricas às novas práticas de intervenção (pp. 45-80). Braga: Psiquilíbrios.

Steinberg, L., \& Silk, J. S. (2002). Parenting adolescents. In M. H. Bornstein (Ed.), Handbook of Parenting: Vol 1: Children and parenting (pp.103-133). Mahwah, NJ: Lawrence Erlbaum Associates.

Thompson, R.A. (1994). Emotion regulation: a theme in search of definition. In N. A. Fox, The development of emotion regulation: behavioral and biological considerations. Monographs of the Society for Research in Child Development, 59 (2-3), p. 25-52.

Thompson, R. A. (2011). Emotion and emotion regulation: Two sides of the developing coin. Emotion Review, 3 (1), 53-61. doi: 10.1177/1754073910380969.

Thompson, R., Smith, G., Osgood, D., Dowd, T., Friman, P. \& Daly, D. (1996). Residential care: A study of short- and long-term educational effects. Children and Youth Services Review, 18 (3), 221-242. doi: 10.1016/0190-7409(96)00002-3.

Trickett, P. K., Negriff, S., Ji, J., \& Peckins, M. (2011). Child maltreatment and adolescent development. Journal of Research on Adolescence, 21(1), 3-20. doi:10.1111/j.1532-7795-2010-00711.x.

Tulviste, T. (2011). Autonomy, educational plans, and self-esteem in institution-reared and home-reared teenagers in Estonia. Youth and Society, 43 (4), 1335-1354. doi: 10.1177/0044118X10384497.

Weis, R., Witemarsh, S. M., \& Wilson, N. L. (2005). Military-style residential treatment for disruptive adolescents: Effective for some girls, all girls, when, and why? Psychological Services, 2 (2), 105-122. 
Running head: The moderating role of length of stay in the relationship between cognitive dysregulation and peer attachment in adolescents living in residential care

doi: 10.1037/1541-1559.2.2.105. 